\title{
Melioidosis, un souvenir caro e inolvidable
}

\author{
Cristina Amado-Fernández', Rebeca González-Peredo², María Dolores González-Soria³, Raquel Portilla-Chocarro', Pilar Fombellida- \\ Gutiérrez $^{2}$ \\ 'Servicio de Medicina Interna. Hospital Sierrallana. Torrelavega (Cantabria). España \\ ${ }^{2}$ Servicio de Urgencias. Hospital Sierrallana. Torrelavega (Cantabria). España \\ ${ }^{3}$ Atención Primaria. Sevilla. España
}

Recibido: 09/12/2018

Aceptado: 20/02/2019

En línea: 30/04/2019

Citar como: Amado-Fernández C, González-Peredo R, González-Soria MD, Portilla-Chocarro R, Fombellida-Gutiérrez P. Melioidosis, un souvenir caro e inolvidable. Rev Esp Casos Clin Med Intern (RECCMI). 2019 (Abr); 4(1): 24-26. doi: 10.32818/reccmi.a4n1a9.

Autor para correspondencia: Cristina Amado-Fernández. cristinaamado@hotmail.com

\section{Palabras clave \\ $\triangleright$ Burkholderia pseudomallei \\ $\triangleright$ Melioidosis \\ $\triangleright$ Osteomielitis}

\begin{abstract}
Resumen
La melioidosis es una enfermedad endémica en el Sudeste Asiático y norte de Australia, e importada a países occidentales como consecuencia del turismo y del tráfico comercial. Es más frecuente en pacientes con diabetes y alcoholismo. Puede producir abscesos cutáneos, neumonía, bacteriemia sin foco y osteomielitis, entre otras afectaciones. El diagnóstico en regiones no endémicas suele retrasarse, lo que aumenta la mortalidad. El tratamiento se basa en el uso de antibióticos combinado con drenaje quirúrgico cuando procede. La mortalidad es elevada, aunque un tratamiento precoz con duración adecuada disminuye el riesgo de recaídas y de muerte. Presentamos el caso de una mujer de 26 años con una osteomielitis tibial por Burkholderia pseudomallei tras un viaje a Tailandia.

Abstract
Melioidosis is an endemic disease in Southeast Asia and Northern Australia. It was introduced to Western
countries as a result of tourism and commercial traffic. It is more frequent in patients with diabetes and
alcoholism. It can produce cutaneous abscesses, pneumonia, bacteremia without focus and osteomye-
litis, among other affectations. The delay in diagnosis in non-endemic regions increases mortality. The
treatment is based on the use of antibiotics combined with surgical drainage when appropriate. Mortality
is high, although early treatment with adequate duration reduces the risk of relapse and death. We present
the case of a 26-year-old woman with tibial osteomyelitis caused by Burkholderia pseudomallei after a
trip to Thailand.
\end{abstract}

\section{Puntos destacados}

$\triangleright$ El diagnóstico en regiones no endémicas se retrasa debido a una baja sospecha.

$\triangleright$ El beneficio para el paciente es mayor cuanto más precoz y adecuado sea el tratamiento antibiótico.

$\triangleright$ Los factores de riesgo asociados a peor evolución son: diabetes, alcohol, talasemia, enfermedad renal, enfermedad pulmonar.

$\triangleright$ El tratamiento se basa en carbapenémicos o ceftazidima.

\section{Introducción}

La melioidosis es una enfermedad causada por Burkholderia pseudomallei (bacteria gramnegativa intracelular facultativa), presente en el medio ambiente ${ }^{1,2}$.
Aunque descrita en 1912, no generó interés hasta que empezó a afectar a muchos soldados en la guerra de Vietnam. Es endémica en el norte de Australia y en el Sudeste Asiático², y se han descrito casos esporádicos en el Caribe, océano Índico (Madagascar), Centroamérica y Sudamérica, y África ${ }^{3,4}$. Fuera de estas regiones, se describe en pacientes que han visitado previamente estos territorios. En España, es una causa poco frecuente de infección, con manifestaciones atípicas, por lo que se debe tener en cuenta este patógeno en los pacientes que han estado recientemente en zonas tropicales o subtropicales, sobre todo en épocas de lluvia ${ }^{3}$. El aumento de los viajes internacionales y del turismo de aventura a zonas endémicas provoca un mayor riesgo de infección a pesar de un corto periodo de exposición $n^{2,3}$.

La transmisión de la infección es por inoculación percutánea, inhalación, aspiración $y$, a veces, ingesta ${ }^{2}$. Antiguamente, la forma de transmisión más frecuente 
era la inhalatoria (inhalación de polvo de los soldados en Vietnam). Actualmente, sin embargo, el modo predominante es la inoculación percutánea tras contacto con suelos húmedos o aguas contaminadas. En época de tormentas tropicales y ciclones, el inhalatorio se considera el principal mecanismo de transmisión. Hay casos documentados de diseminación hematógena (a partir de heridas cutáneas). La transmisión entre personas es inusual', a pesar de la elevada carga bacteriana en los pacientes graves. Se puede transmitir de madre a hijo a través de lactancia en casos de mastitis ${ }^{5}$. La transmisión sexual, así como por animales, es extremadamente rara.

\section{Caso clínico}

Exponemos el caso de una mujer de 26 años sin antecedentes medicoquirúrgicos de interés que consultó en el mes de diciembre en el Servicio de Urgencias de nuestro hospital por odinofagia, rinorrea, tos seca y fiebre. Como antecedente relevante, había regresado 15 días antes de un viaje por zonas rurales del Sudeste Asiático (Tailandia). En su primera visita a Urgencias, recibió tratamiento con antitérmicos y antibioterapia (amoxicilina y azitromicina). Una semana después, acudió de nuevo por astenia y adenopatías laterocervicales. Se realizó una analítica básica, radiografía de tórax, hemocultivos y urocultivo, destacando PCR de184 mg/l (0-5). Se solicitó consulta preferente en Medicina Interna.

Tras 2 semanas, comenzó con dolor a nivel pretibial derecho y fiebre de predominio nocturno. La exploración física fue nuevamente normal, sin objetivarse artritis, y la radiografía de tibia derecha fue normal. Analíticamente, presentaba VSG $120 \mathrm{~mm} / \mathrm{h}$

Durante el seguimiento en consultas, apareció eritema y tumefacción loca a nivel de cara anterior de la pierna derecha, y se objetivaron en la radiografía lesiones líticas en el tercio superior de la tibia. Se realizó tomografía axial computarizada (TAC) (Figura 1) de pierna, que fue sugestiva de osteomielitis en metáfisis y diáfisis proximal de tibia.

Se realizó biopsia-aspirado obteniéndose pus franco ( $90 \mathrm{ml}$ ), aislándose Burkholderia pseudomallei. Se inició tratamiento antibiótico empírico con ertapenem $1 \mathrm{~g} / 24$ h y vancomicina $1 \mathrm{~g} / 12$ h, y la paciente ingresó para realizar osteotomía y desbridamiento con lavado y relleno de cavidad ósea con cemento impregnado de antibiótico (vancomicina + gentamicina), asociado a ceftazidima $2 \mathrm{~g} / 8$ h. Se mantuvo tratamiento intravenoso durante 4 semanas con cefta- zidima. El tratamiento con trimetoprim/sulfametoxazol oral (320/1.600 mg/12 h) se prolongó durante un año por la evolución tórpida inicial de la paciente. Actualmente asintomática, sigue revisiones en consulta de Medicina Interna y Traumatología.

\section{Discusión y conclusiones}

La mayoría de las infecciones por Burkholderia son asintomáticas. El periodo de incubación es entre 1-21 días ${ }^{2,5}$. La infección puede ser aguda (menos de 2 meses) o crónica (más de 2 meses) ${ }^{2}$. La forma de presentación más frecuente es la enfermedad aguda. Las manifestaciones clínicas más habituales son la neumonía (51\%), la infección genitourinaria (14\%), la infección cutánea (13\%), la bacteriemia sin foco (11\%), la artritis séptica con o sin osteomielitis (4\%) y la afectación neurológica (3\%). El 4\% restante no presenta foco evidente de infección. Más del 50\% de los pacientes tiene bacteriemia en el momento de la infección, y en uno de cada cinco pacientes se desarrolla shock séptico².

Son frecuentes los abscesos en órganos internos y focos secundarios en pulmones y/o articulaciones. Las manifestaciones clínicas severas se dan fundamentalmente en pacientes con factores de riesgo, entre los que se incluyen diabetes, alcohol, enfermedad renal crónica, enfermedad pulmonar crónica, talasemia, empleo de glucocorticoides y cáncer ${ }^{2,5}$. Sin embargo, las manifestaciones fulminantes se pueden presentar en individuos sanos. Aunque la literatura revisada muestra un bajo porcentaje de afectación ósea dentro de las manifestaciones de la infección, en nuestro caso sospechamos que se produjo una diseminación hematógena a partir de una infección respiratoria.

El diagnóstico se basa en la clínica y la epidemiología, así como en cultivos². Se deben realizar hemocultivos, cultivo de lesiones y abscesos, urocultivo, frotis rectal y faríngeo. La PCR no es suficientemente específica, la serología no es rentable. El cultivo se realiza en medio agar enriquecido que permite el crecimiento selectivo de Burkholderia pseudomallei. Se debe hacer diagnóstico diferencial con infección por Mycobacterium tuberculosis, principalmente.

El tratamiento se basa fundamentalmente en carbapenémicos y ceftazidima ${ }^{1}$ 2. Burkholderia es característicamente resistente a penicilina, ampicilina, cefalosporinas de primera y segunda generación y aminoglucósidos ${ }^{2}$. Las recomendaciones de tratamiento son: ceftazidima $2 \mathrm{~g} / 6 \mathrm{~h}$, meropenem $1 \mathrm{~g} / 8 \mathrm{~h}$ o
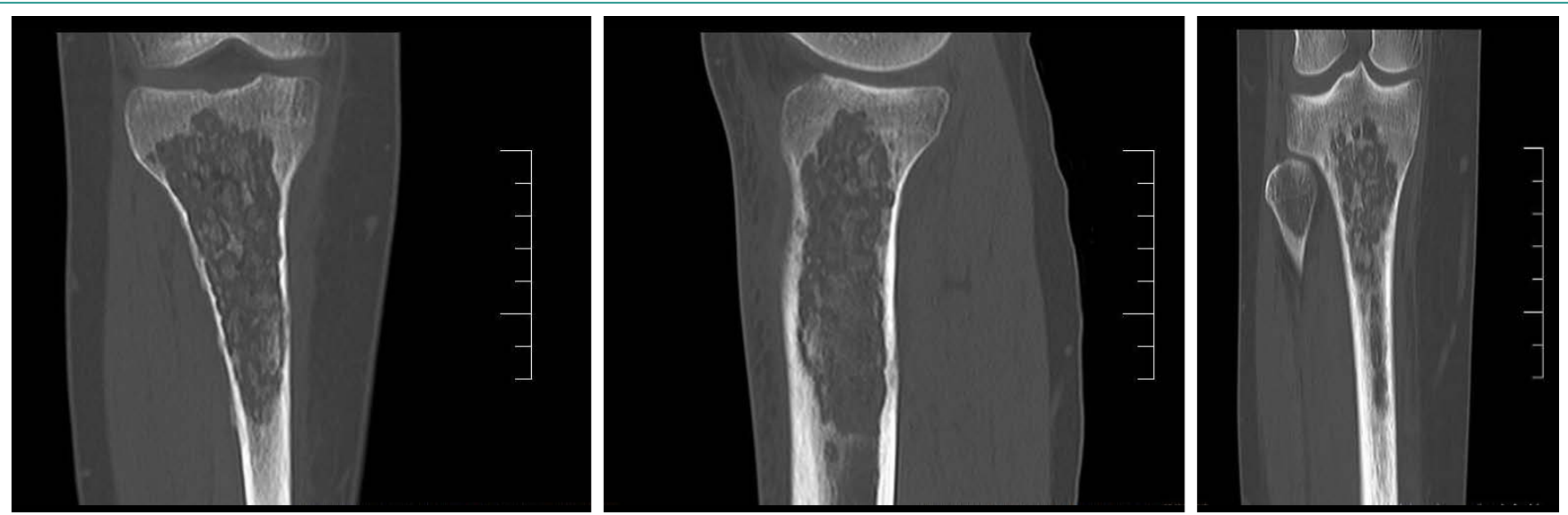

Figura 1. Extensa lesión endomedular en la metáfisis y diáfisis proximal de la tibia derecha con leve extensión hacia la epíisis, que ocupa la casi totalidad de la cavidad medular, condicionando reabsorción endóstica con adelgazamiento cortical secundario en las corticales anteromedial y anterolateral de la diáfisis, adyacentes a la tuberosidad tibial anterior 
imipenem $1 \mathrm{~g} / 6 \mathrm{~h}$. El tratamiento intravenoso se alarga al menos 2 semanas completándolo con tratamiento oral con trimetoprim/sulfametoxazol hasta un total de 3 meses (6 meses en afectación neurológica y osteomielitis) $)^{6,7}$. Se debe realizar drenaje de los abscesos junto con el tratamiento antibiótico para lograr control del foco infeccioso ${ }^{6,7}$ (Tabla 1 y Tabla 2).

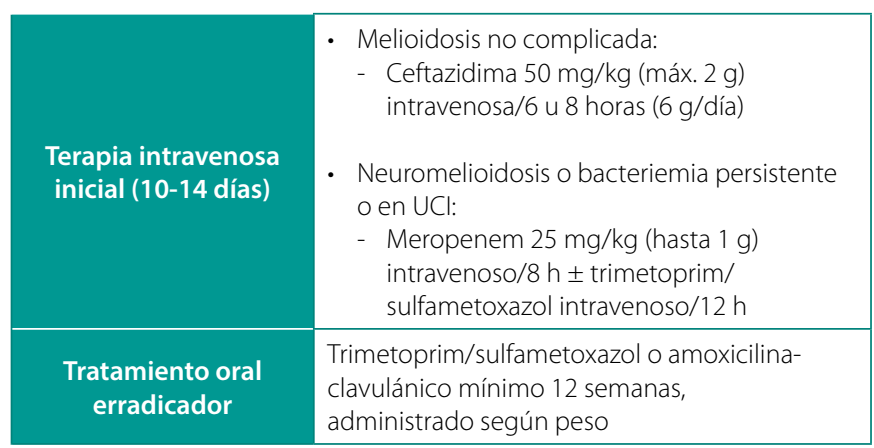

Tabla 1. Tratamiento antibiótico de la melioidosis ${ }^{6}$

\begin{tabular}{|l|c|c|}
\multicolumn{1}{|c|}{ Foco clínico } & $\begin{array}{c}\text { Fase intravenosa } \\
\text { mínima }\end{array}$ & $\begin{array}{c}\text { Fase erradicadora } \\
\text { oral }\end{array}$ \\
\hline Absceso piel & 2 semanas & 3 meses \\
\hline Bacteriemia sin foco & 2 semanas & 3 meses \\
\hline Neumonía & 2 a 4 semanas & 3 meses \\
\hline $\begin{array}{l}\text { Absceso prostático, artritis } \\
\text { séptica, colección en órganos } \\
\text { o tejidos profundos }\end{array}$ & 4 semanas & 3 meses \\
\hline Osteomielitis & 6 semanas & 6 meses \\
\hline Infección del SNC & 8 semanas & 6 meses \\
\hline Aneurismas micóticos & meses \\
\hline
\end{tabular}

Tabla 2. Guía Darwin de melioidosis? . Duración del tratamiento antibiótico en infecciones por Burkholderia pseudomallei (melioidosis)

En nuestro caso, el diagnóstico requirió un elevado grado de sospecha y la confirmación microbiológica, obtenido por las muestras quirúrgicas, y siendo clave en el diagnóstico el viaje a zonas endémicas ${ }^{8}$.
El riesgo de recaídas se debe a un tratamiento incompleto o erradicación faIlida (más que por una nueva infección). Si no hay bacteriemia, el tratamiento es erradicador y el pronóstico es excelente. La mortalidad es elevada, hasta un $40 \%$ en países en vías de desarrollo, y un 14\% en el resto 2.

Gran parte de las exposiciones no generan una infección activa, pero pueden reactivarse después de años de la infección primaria, luego requieren seguimiento a largo plazo.

\section{Bibliografía}

1. García-Ramos SE, García-Poza P, Marabé-Carretero G, De Miguel-Prieto J. Update in the treatment of melioidosis. A case study. Farm Hosp. 2011 Nov-Dec; 35(6): 344-346. doi: 10.1016/j.farma.2010.09.010.

2. Nasner-Posso KM, Cruz-Calderón S, Rodríguez-Morales AJ, Montufar-Andrade FE. Melioidosis: a sporadic or an emerging disease in Colombia? Enferm Infecc Microbiol Clin. 2015 Mar; 33(3): 206-207. doi: 10.1016/j. eimc.2014.10.013.

3. Guzmán-Gómez L, Agudo Bilbao M, Peiro-Callizo E, Salas C. Melioidosis imported from Colombia to Spain. Enferm Infecc Microbiol Clin. 2015 Mar; 33(3): 214-216. doi: 10.1016/j.eimc.2014.06.003.

4. Morosini MI, Quereda C, Gil H, Anda P, Núñez-Murga M, Cantón R, LópezVélez R. Melioidosis in traveler from Africa to Spain. Emerg Infect Dis. 2013 Oct; 19(10): 1656-1659. doi: 10.3201/eid1910.121785.

5. Currie BJ, Ward L, Cheng AC. The epidemiology and clinical spectrum of melioidosis: 540 cases from the 20 year Darwin prospective study. PLoS Negl Trop Dis. 2010 Nov 30; 4(11): e900. doi: 10.1371/journal. pntd.0000900.

6. Dance D. Treatment and prophylaxis of melioidosis. Int J Antimicrob Agents. 2014 Apr; 43(4): 310-318. doi: 10.1016/j.ijantimicag.2014.01.005.

7. Pitman MC, Luck T, Marshall CS, Anstey NM, Ward L, Currie BJ. Intravenous therapy duration and outcomes in melioidosis: a new treatment paradigm. PLoS Negl Trop Dis. 2015 Mar 26; 9(3): e0003586. doi: 10.1371/ journal.pntd.0003586.

8. Popoff I, Nagamori J, Currie B. Melioidotic osteomyelitis in northern Australia. Aust N Z J Surg. 1997 Oct; 67(10): 692-695. 